\title{
Prognostic value of pretreatment albumin-globulin ratio in predicting long-term mortality in gastric cancer patients who underwent D2 resection
}

This article was published in the following Dove Press journal:

OncoTargets and Therapy

13 April 2017

Number of times this article has been viewed

\author{
Jianjun Liu',2,* \\ Shangxiang Chen ${ }^{1,2, *}$ \\ Qirong Geng ${ }^{1,3}$ \\ Xuechao Liu'1,2 \\ Pengfei Kong ${ }^{1,2}$ \\ Youqing Zhan ${ }^{1,2}$ \\ Dazhi $X u^{1,2}$
}

'State Key Laboratory of Oncology in South China, Collaborative Innovation Center for Cancer Medicine, ${ }^{2}$ Department of Gastric and Pancreatic Surgery, Sun Yat-sen University Cancer Center, ${ }^{3}$ Department of Hematology Oncology, Sun Yat-sen University Cancer Center, Guangzhou, People's Republic of China

*These authors contributed equally to this work
Background: Several studies have highlighted the prognostic value of the albumin-globulin ratio (AGR) in various kinds of cancers. Our study was designed to assess whether AGR is associated with the prognosis of gastric cancer patients.

Patients and methods: A total of 507 gastric cancer patients between 2005 and 2012 were included. The AGR was defined as the ratio of serum albumin to nonalbumin and calculated by the equation: albumin/(total protein - albumin). Furthermore, AGR was divided into two groups (low and high) using the X-tile software. Survival analysis stratified by AGR groups was performed.

Results: The mean survival time for each group was 36.62 months (95\% CI: 33.92-39.32) for the low AGR group and 48.95 months (95\% CI: 41.93-55.96, $P=0.003$ ) for the high AGR group. Patients in the high group (AGR $\geq 1.93$ ) had a significantly lower 5-year mortality in comparison with the low group (AGR < 1.93) (52.4\% vs 78.5\%, $P=0.003)$. The high AGR group showed obviously better overall survival than the low AGR group according to Kaplan-Meier curves $(P=0.003)$. Multivariate analysis showed that AGR was an independent predictive factor of prognosis in gastric patients.

Conclusion: Pretreatment AGR is a significant and independent predictive factor of prognosis.

Keywords: gastric cancer, survival, inflammation, albumin-globulin ratio

\section{Introduction}

Although incidence of gastric cancer has fallen markedly in the recent years, it still remains one of the most common cancers. Gastric cancer is the second leading cause of cancer-related death, and the 5-year survival was $28 \%$ in $2014 .{ }^{1}$ Most of the patients are found to be at locally advanced stage by the time of diagnosis, which consequently leads to poorer quality of life and shorter survival. Although some prognostic markers such as the modified Glasgow Prognostic Score, ${ }^{2,3}$ neutrophil-lymphocytes ratio (NLR), ${ }^{4,5}$ and platelet-lymphocytes ratio ${ }^{5}$ have already been demonstrated to be valuable in gastric cancer, exploration for the serum albumin-globulin ratio (AGR) has not been performed yet. There is a need to explore the association between the prognosis of gastric cancer and AGR.

Besides some other inflammatory proteins (such as C-reactive protein, interleukins, and tumor necrosis factors), ${ }^{6}$ human total protein contains two main constituents, serum albumin (35-55 g/L) and globulin (20-35 g/L). Serum albumin has been mentioned to be associated with the nutrition status and the progression of several diseases. ${ }^{7}$ Previous studies have shown that low albumin level is associated with the poor prognosis of
Correspondence: Dazhi Xu Department of Gastric and Pancreatic Surgery, Sun Yat-sen University Cancer Center, 65I\# East Dongfeng Road, Guangzhou 510060, Guangdong Province, People's Republic of China Email xudzhi@sysucc.org.cn 
several cancers, such as gastric, ${ }^{8}$ colorectal, ${ }^{9-12}$ pancreatic, ${ }^{13}$ lung, ${ }^{14}$ ovarian cancers, ${ }^{14,15}$ and so on. Albumin and globulin play an important role in immunity and inflammation; they are valuable predictors in the progress of diseases. ${ }^{16}$ However, both the chemical predictors are easily affected by other factors such as dehydration and edema, which influence their value of efficiency and accuracy. Thus, our study attempted to explore a reliable index combined by serum albumin and globulin, by putting these two indexes together. The AGR ratio was calculated using the equation: albumin/ (total protein - albumin). To the best of our knowledge, we are the first to explore the association between AGR and the prognosis of gastric cancer.

\section{Patients and methods}

\section{Ethics statement}

This study complied with the standards of the Declaration of Helsinki and was approved by the Ethical Committees of Sun Yat-sen University Cancer Center. Patients who signed informed consent were included.

\section{Study population and data collection}

Patients hospitalized between June 2005 and December 2012 were enrolled in this study, all of whom were treated at the Department of Gastropancreatic Surgery, Sun Yat-sen Cancer Center, Guangzhou, People's Republic of China. A total of 507 cases of this cohort matched our inclusion and exclusion criteria. The inclusion criteria were as follows: 1) patients with pathologically or histologically proven gastric cancer; 2) Patients with no acute or chronic inflammation, immune disease, hematological disease, liver disease, or concomitant cancer, which could influence the level of the proteins; 3) Patients for whom complete biochemistry index and blood data were available before surgery, chemotherapy, and radiotherapy; 4) All the patients who underwent D2 curative resection at last (thus, patients in stage IV were excluded); 5) Patients who were staged according to the tumor node metastasis criteria (American Joint Committee on Cancer [AJCC] criteria seventh edition). ${ }^{17}$

Various clinical variables were investigated, including age, sex, tumor size, differentiated type, the depth of invasion, lymph node status, AJCC stage, location, tumor markers, and laboratory variables (Table 1). The depth of invasion (T), the lymph node status $(\mathrm{N})$, the presence of metastasis $(\mathrm{M})$, and the AJCC stage for every patient were obtained from the data in our hospital cancer registry. ${ }^{17}$ For survival analysis, we divided the patients into two groups according to the best cutoff value obtained by the software X-tile software Version 3.6.1 (Yale University School of Medicine, New Haven, CT, USA). The low AGR group comprised 440 patients and had lower AGR
Table I Baseline characteristics of 507 gastric cancer patients stratified by pretreatment AGR groups

\begin{tabular}{|c|c|c|c|}
\hline Variable & $\begin{array}{l}\text { Lower } \\
\text { AGR group } \\
\text { AGR }<\text { I.93 }\end{array}$ & $\begin{array}{l}\text { Higher } \\
\text { AGR group } \\
\text { AGR } \geq 1.93\end{array}$ & $P$-value \\
\hline Total study & 440 & 67 & \\
\hline \multicolumn{4}{|l|}{ Age (years) } \\
\hline$<60 / \geq 60$ & $214 / 226$ & $40 / 27$ & $<0.001$ \\
\hline Gender (male/female) & $290 / 150$ & $58 / 9$ & 0.001 \\
\hline \multicolumn{4}{|l|}{ Differentiated type } \\
\hline Well/moderate and poor & $82 / 358$ & $18 / 49$ & 0.005 \\
\hline \multicolumn{4}{|l|}{ Tumor size } \\
\hline$(<6 \mathrm{~cm} / \geq 6 \mathrm{~cm})$ & $70 / 370$ & $65 / 2$ & 0.057 \\
\hline Location (upper/middle/lower) & $216 / 73 /|5|$ & $30 / 7 / 30$ & 0.178 \\
\hline T stage $(\mathrm{TI} / \mathrm{T} 2 / \mathrm{T} 3 / \mathrm{T} 4)$ & $36 / 33 / 103 / 268$ & $10 / 5 / 7 / 45$ & 0.015 \\
\hline Node stage (N0/NI/N2/N3) & $107 / 48 / 85 / 200$ & $21 / 11 / 11 / 24$ & 0.294 \\
\hline AJCC stage $(I / I I / I I I)$ & $47 / 89 / 304$ & $12 / 12 / 43$ & 0.014 \\
\hline Total protein $(g / L)$ & $66.9 \pm 7.1$ & $62.8 \pm 5.3$ & 0.010 \\
\hline Albumin $(g / L)$ & $39.8 \pm 4.7$ & $42.7 \pm 3.5$ & 0.012 \\
\hline Globulin (g/L) & $26.8 \pm 4.2$ & $20.7 \pm 2.9$ & $<0.001$ \\
\hline Blood platelet & $257.5 \pm 102.0$ & $230.0 \pm 68.2$ & 0.014 \\
\hline White blood cell $\left(\times 10^{9} / L\right)$ & $7.0 \pm 2.7$ & $6.8 \pm 2.8$ & 0.520 \\
\hline Neutrophil $\left(\times 10^{9} / \mathrm{L}\right)$ & $4.4 \pm 2.5$ & $4.3 \pm 2.6$ & 0.889 \\
\hline Lymphocyte (×109/L) & $1.9 \pm 0.7$ & $1.9 \pm 0.6$ & 0.068 \\
\hline Hemoglobin $(g / L)$ & $121.0 \pm 23.7$ & $130.6 \pm 22.7$ & 0.475 \\
\hline C-reactive protein (mg/L) & $|2.7 \pm 3| .3$ & $5.93 \pm 23.4$ & 0.013 \\
\hline
\end{tabular}

Note: The continuous variables were presented as mean \pm SD and categorical variables were presented as frequency.

Abbreviations: AGR, albumin-globulin ratio; AJCC, American Joint Committee on Cancer; SD, standard deviation.

value, and the high AGR group comprised 67 patients and had higher low AGR value $(<1.93)$. Survival status of each group was analyzed, and the primary end point was death due to any causes. The follow-up ended in December 2014, and the data were obtained from our hospital cancer registry. The follow-up duration was defined as the time between the day when the operation was performed until the day cancer recurred or the patient died of any other causes, and overall survival time was defined as the time between the operation and death or the last follow-up.

\section{X-tile analysis}

The X-tile software Version 3.6.1 (Yale University School of Medicine) was used to discover the optimal cutoff points of the AGR based on the outcome. X-plots generated by the software were used to evaluate the expression level of the AGR. The assessment of statistical significance was performed by corrected $P$-value, which was produced by log-rank test (Figure 1). ${ }^{18}$

\section{Statistical analysis}

All statistical analyses were performed by the software Statistical Package for Social Sciences Version 19.0 

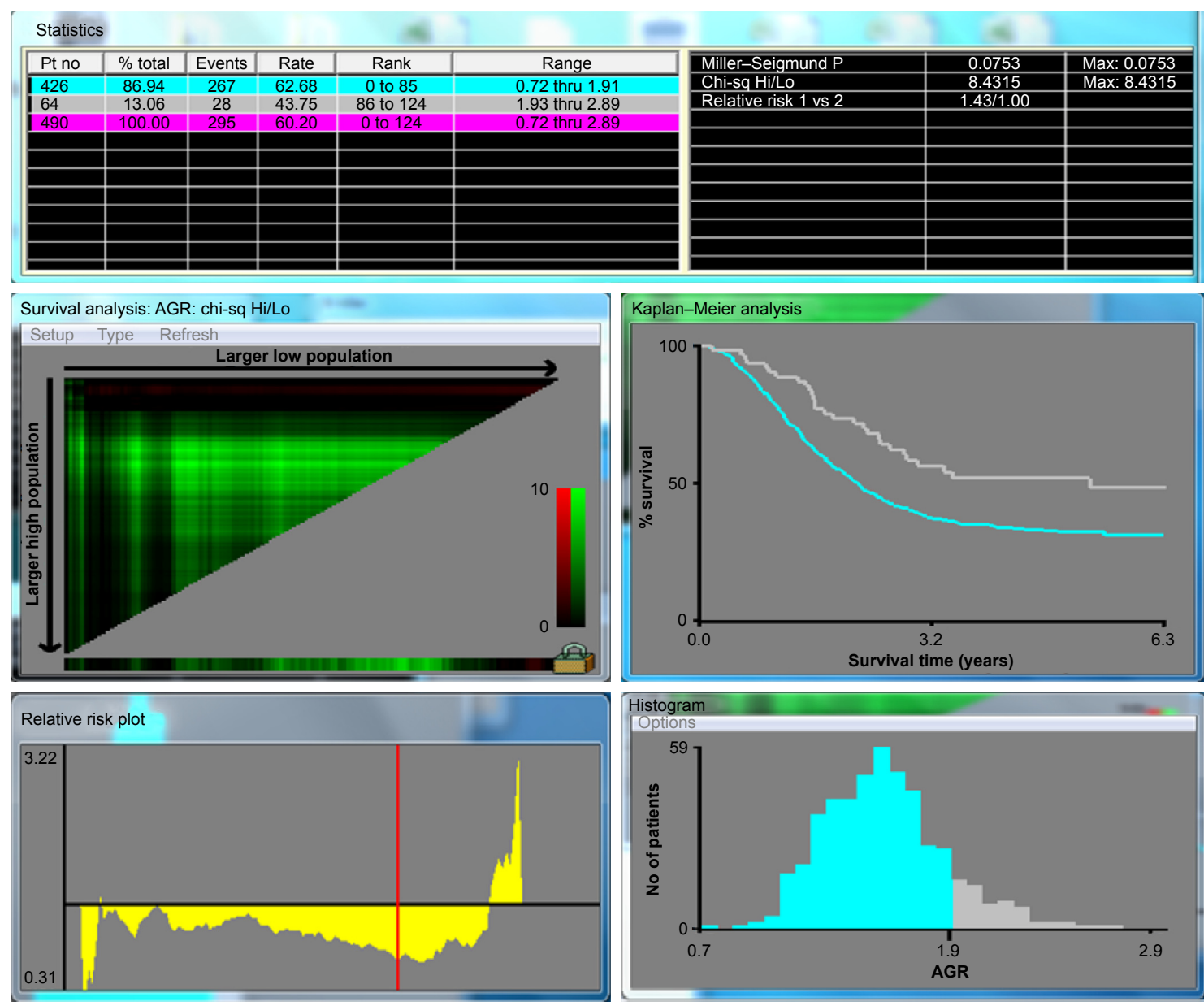

Figure I X-Tile analysis of prognosis based on AGR groups; X-tile plots showing overall survival in different AGR groups.

Abbreviation: AGR, albumin-globulin ratio.

(SPSS, Chicago, IL). A result was considered statistically significant only when the $P$-value was $<0.05$. The two AGR groups were analyzed using the chi-square test for categorical variables and the Kruskal-Wallis test for continuous variables. The continuous variables were presented as mean $\pm \mathrm{SD}$ and categorical variables were presented as frequency. We analyzed the differences of survival status between each AGR group. Furthermore, in case of the influence of low serum albumin and short-term mortality, differences of post-6-month survivors and patients with normal serum albumin (albumin $\geq 35 \mathrm{~g} / \mathrm{L}$ ) were also analyzed, in which the Kaplan-Meier curves and log-rank test were used. Additional analysis was done to explore the association between calculated globulin and prognosis. All the promising predictors in Table 1 were analysed with a univariate Cox proportional hazards model separately. The variable would enter a multivariate analysis if it was statistically and clinically significant. Entry selection was used to exclude the factors that did not make much difference to this Cox model and to add new meaningful variables.
Subsequently, survival analysis was performed by these professional methods and principles.

\section{Results}

Mean age of our study population was 58.8 years, 348 (68.6\%) were males, $100(19.7 \%)$ were well/moderately differentiated, and $135(26.6 \%)$ had tumor size $<6 \mathrm{~cm}^{2}$. The number of patients with upper, middle, and lower tumor were 246,80 , and 181, respectively, and 59, 101, 347 for stage I, II, III patients. Inflammation markers (eg, neutrophil count and C-reactive protein) in the low AGR group were significantly higher than those in the high AGR group; however, hemoglobin count was higher in the high AGR group and albumin was lower in the low AGR group (Table 1).

The mean survival time for each group was, for the low AGR group 36.62 months (95\% CI [confidence interval]: 33.92-39.32), and for the high AGR group 48.95 months (95\% CI: 41.93-55.96; $P=0.003$ ). Patients in the high AGR group (AGR $\geq 1.93$ ) had a significantly lower 5 -year mortality in comparison with the low AGR group 
(AGR $<1.93 ; 52.4 \%$ vs $78.5 \%, P=0.003$ ). The high AGR group showed obviously better overall survival than the low AGR group according to Kaplan-Meier curves $(P=0.003$; Figure 2A). Serum albumin (39.8 \pm 4.7 vs 42.7 $\pm 3.5, P=0.012)$ and AGR values (AGR $<1.93$ vs AGR $\geq 1.93$ ) in the high AGR group were clearly higher than that of the low AGR group, while globulin $(26.8 \pm 4.2$ vs $20.7 \pm 2.9)$ in the low AGR group was higher than that of the high AGR group. Furthermore, when we excluded the patients who died in the first 6 months of follow-up, the 5-year mortality rates were $244 / 392(62.2 \%)$ and 28/64 (43.8\%) for the low and high
AGR groups, respectively ( $P=0.011$; Figure $2 \mathrm{~B}$ ). The same conclusion was drawn in the patients whose serum albumin was $\geq 35 \mathrm{~g} / \mathrm{L}$, and the 5 -year mortality rates for the low AGR group and the high AGR group were 224/373 (60.0\%) and 29/66 (43.9\%, $P=0.009$; Figure 2C), respectively. When we divided the population into two groups according to the calculated globulin, the low globulin group showed better survival in both the total population $(P=0.005$; Figure $3 \mathrm{~A})$ and the patients whose serum albumin was $\geq 35 \mathrm{~g} / \mathrm{L}$ ( $P<0.001$; Figure $3 \mathrm{~B})$. Association between each variable and overall survival is presented in Table 2, in which univariate Cox regression
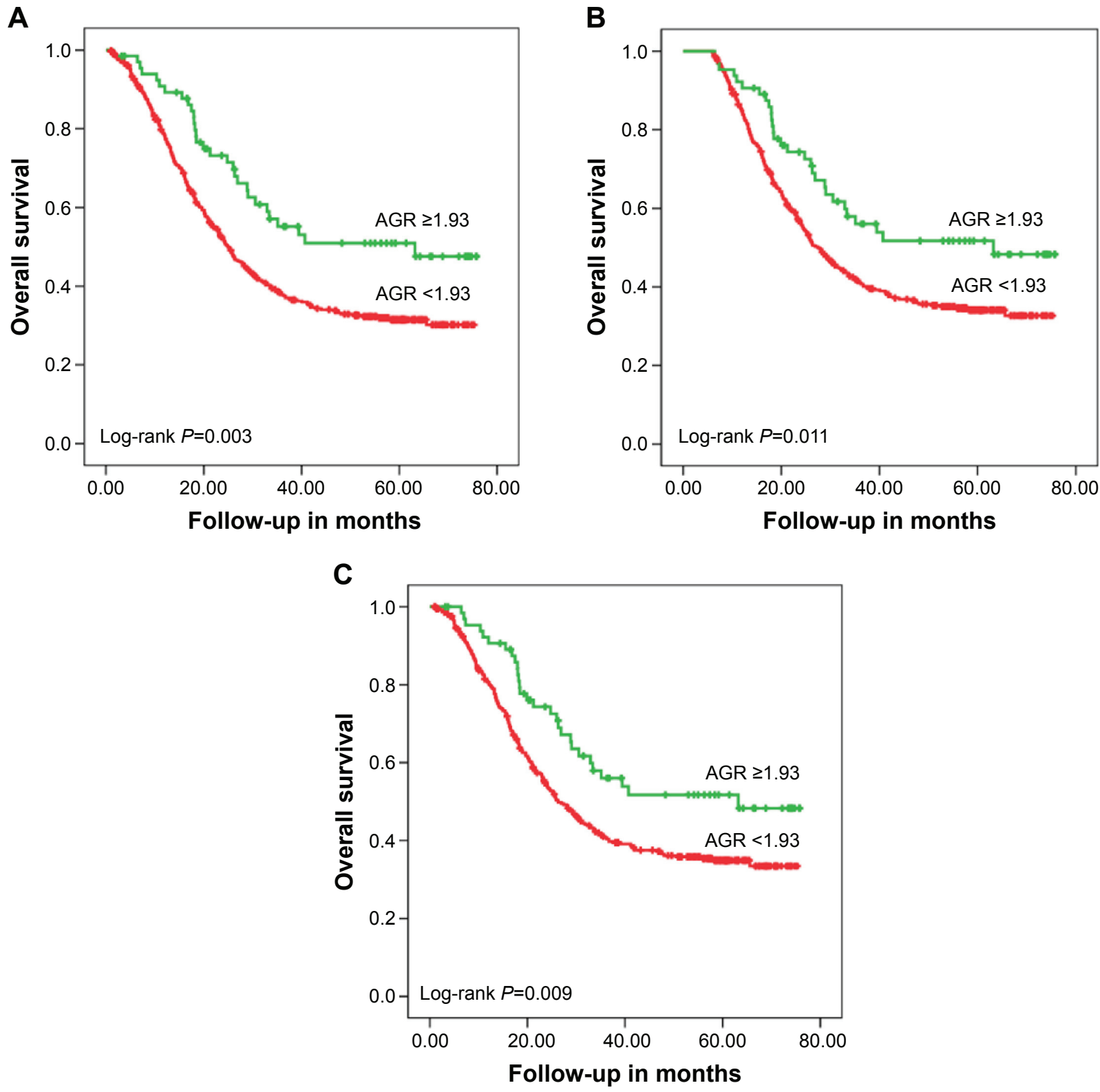

Figure 2 Kaplan-Meier analyses of overall survival.

Notes: Survival analyses of total population stratified by AGR groups (A). Post-6-month survival according to AGR groups (B). Survival analyses of study patients (serum albumin $\geq 35 \mathrm{~g} / \mathrm{L}$ ) by AGR groups (C).

Abbreviation: AGR, albumin-globulin ratio. 

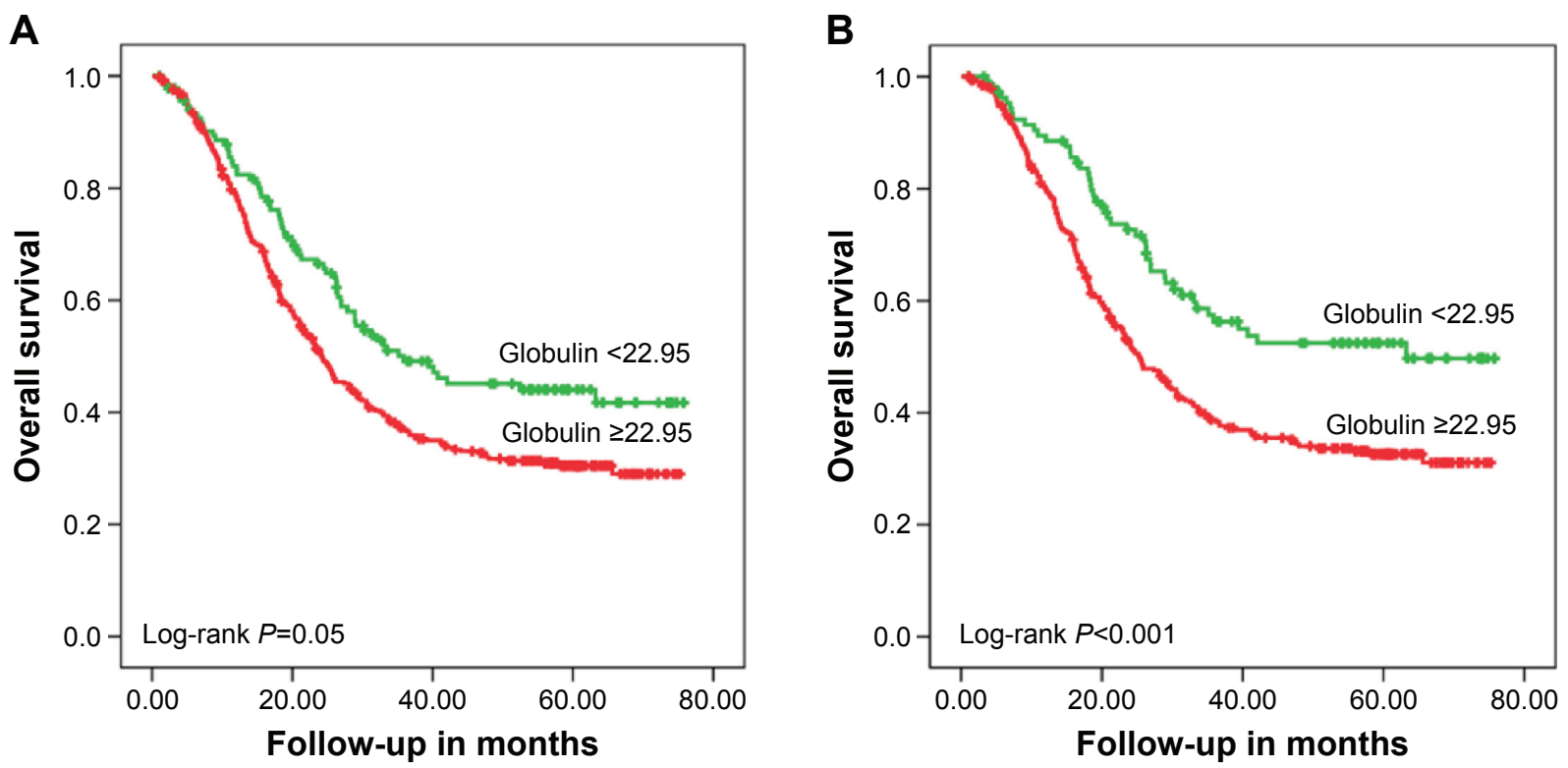

Figure 3 Kaplan-Meier analyses of overall survival according to the level of globulin ( $g / \mathrm{L})$

Notes: Survival analyses of total population stratified by globulin groups $(\mathbf{A})$. Survival analyses of study patients (serum albumin $\geq 35 \mathrm{~g} / \mathrm{L})$ by globulin groups $(\mathbf{B})$.

was performed. Table 2 shows that age, tumor size, node stage, AJCC stage, T stage, White blood cell (WBC) count, globulin count, neutrophil count, and C-reactive protein count were higher in those patients who had higher mortality rates. Patients with higher total protein, albumin count, lymphocyte count, and hemoglobin count shared lower mortality rates. Lower mortality was fairly apparent in patients with high AGR value $(P=0.003)$. In addition, the hazard ratio of the patients in the low AGR group increased by $1.755(P=0.003)$ when compared with the high group (Table 2).

Variables associated with overall survival in the univariate Cox regression model were included in the Cox proportional hazard multivariate model. In consideration of the high degree of correlation between AJCC stage and $\mathrm{T} / \mathrm{N}$ stage, two separate analyses were performed. Model 1 (including variables such as age, location, AJCC stage, NLR, and AGR) and Model 2 (including variables such as age, location, $\mathrm{N}$ stage, $\mathrm{T}$ stage, NLR, and AGR) showed that AGR is an independent predictor of prognosis in gastric cancer patients (Table 3), with HR value even higher than NLR (Model 1: 1.374 vs 1.062 and Model 2: 1.489 vs 1.072).

\section{Discussion}

Albumin, which is one of the proteins produced in the liver, has been shown to maintain the osmotic pressure and act as a free radical scavenger. ${ }^{19}$ Albumin was useful in evaluating nutrition status, disease regression, and prognosis in patients. ${ }^{19,20}$ For example, hypoalbuminemia usually implied situation such as malnutrition, chronic inflammation,
Table 2 Hazard ratios of baseline characteristics for all-cause mortality in gastric cancer patients (univariate analysis)

\begin{tabular}{|c|c|c|}
\hline Variable & Hazard ratio $(95 \% \mathrm{Cl})$ & $P$-value ${ }^{a}$ \\
\hline Age $(\geq 60 /<60$ years $)$ & $1.020(1.010-1.029)$ & $<0.001$ \\
\hline Sex (male/female) & $0.922(0.780-1.263)$ & 0.950 \\
\hline Tumor size $(\geq 6 \mathrm{~cm} /<6 \mathrm{~cm})$ & $2.57 \mid(1.772-3.730)$ & $<0.001$ \\
\hline $\begin{array}{l}\text { Differentiated type } \\
\text { (well/moderate and poor) }\end{array}$ & $0.900(0.68 I-I .189)$ & 0.458 \\
\hline \multicolumn{3}{|l|}{ Location (ref: lower) } \\
\hline Upper & 2.148 (1.652-2.793) & $<0.001$ \\
\hline Middle & $1.519(1.016-2.175)$ & 0.023 \\
\hline \multicolumn{3}{|l|}{ T stage (ref: TI) } \\
\hline $\mathrm{T} 2$ & $2.599(1.037-6.515)$ & 0.042 \\
\hline T3 & $6.887(3.163-14.995)$ & $<0.001$ \\
\hline $\mathrm{T} 4(\mathrm{a} / \mathrm{b})$ & 7.420 (3.49I-15.770) & $<0.001$ \\
\hline \multicolumn{3}{|l|}{ Node stage (ref: N0) } \\
\hline $\mathrm{NI}$ & $2.564(1.563-4.206)$ & $<0.001$ \\
\hline N2 & 3.927 (2.576-5.987) & $<0.001$ \\
\hline N3 & $6.548(4.496-9.538)$ & $<0.001$ \\
\hline \multicolumn{3}{|l|}{ AJCC stage (ref: I) } \\
\hline Stage II & $4.83 \mid$ (2.05I-II.382) & $<0.001$ \\
\hline Stage III & I4.393 (6.394-32.40I) & $<0.001$ \\
\hline Total protein (g/L) & 0.991 (0.974-I.007) & 0.267 \\
\hline Albumin $(g / L)$ & $0.959(0.937-0.982)$ & $<0.001$ \\
\hline Globulin $(g / L)$ & I.0II (0.987-I.035) & 0.380 \\
\hline White blood cell $\left(\times 10^{9} / \mathrm{L}\right)$ & 1.061 (I.019-1.104) & 0.004 \\
\hline Blood platelet $\left(\times 10^{9} / \mathrm{L}\right)$ & $1.000(0.999-1.00 I)$ & 0.801 \\
\hline Neutrophil $\left(\times 10^{9} / \mathrm{L}\right)$ & 1.099 (I.056-I.I44) & $<0.001$ \\
\hline Lymphocyte (×109/L) & $0.743(0.626-0.882)$ & 0.001 \\
\hline Hemoglobin $(g / L)$ & $0.998(0.994-1.003)$ & 0.492 \\
\hline C-reactive protein (mg/L) & $1.010(1.007-1.013)$ & $<0.001$ \\
\hline $\operatorname{AGR}(<1.93 / \geq 1.93)$ & 1.755 (1.204-2.559) & 0.003 \\
\hline
\end{tabular}

Note: a Log-rank test.

Abbreviations: AGR, albumin-globulin ratio; AJCC, American Joint Committee on Cancer; $\mathrm{Cl}$, confidence interval. 
Table 3 Hazard ratios for all-cause mortality in gastric cancer patients (multivariate analysis)

\begin{tabular}{|c|c|c|}
\hline Variable & Hazard ratio $(95 \% \mathrm{Cl})$ & $P$-value ${ }^{a}$ \\
\hline \multicolumn{3}{|l|}{ Model I } \\
\hline Age $(\geq 60 /<60$ years $)$ & 1.259 (I.038-I.527) & 0.02 \\
\hline \multicolumn{3}{|l|}{ Location (ref: lower) } \\
\hline Upper & $1.293(1.036-1.613)$ & 0.023 \\
\hline Middle & $1.25 \mid(0.935-1.673)$ & 0.131 \\
\hline \multicolumn{3}{|l|}{ AJCC stage (ref: I) } \\
\hline Stage II & 1.704 (I.II4-2.608) & 0.014 \\
\hline Stage III & $3.796(2.587-5.569)$ & $<0.001$ \\
\hline NLR (per unit) & $1.062(1.032-1.094)$ & $<0.001$ \\
\hline $\operatorname{AGR}(<1.93$ vs $\geq 1.93)$ & $1.374(1.020-1.851)$ & 0.037 \\
\hline \multicolumn{3}{|l|}{ Model 2} \\
\hline Age $(<60 / \geq 60$ years $)$ & 1.568 (1.237-1.988) & $<0.001$ \\
\hline \multicolumn{3}{|l|}{ Location (ref: lower) } \\
\hline Upper & 1.589 (1.206-2.093) & 0.001 \\
\hline Middle & $1.305(0.902-1.887)$ & 0.158 \\
\hline \multicolumn{3}{|l|}{ Node stage (ref: N0) } \\
\hline $\mathrm{NI}$ & $2.183(1.299-3.668)$ & 0.003 \\
\hline N2 & $2.837(1.803-4.465)$ & $<0.001$ \\
\hline N3 & $5.246(3.479-7.909)$ & $<0.001$ \\
\hline \multicolumn{3}{|l|}{ T stage (ref: TI) } \\
\hline $\mathrm{T} 2$ & $1.422(0.5 \mid 7-2.908)$ & 0.495 \\
\hline T3 & $2.661(1.114-6.306)$ & 0.028 \\
\hline $\mathrm{T} 4(\mathrm{a} / \mathrm{b})$ & $2.877(1.229-6.735)$ & 0.015 \\
\hline NLR (per unit) & $1.072(1.040-1.104)$ & $<0.001$ \\
\hline $\operatorname{AGR}(<1.93 / \geq 1.93)$ & 1.489 (1.004-2.208) & 0.048 \\
\hline
\end{tabular}

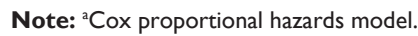

Abbreviations: AGR, albumin-globulin ratio; NLR, neutrophil-lymphocyte ratio; AJCC, American Joint Committee on Cancer; $\mathrm{Cl}$, confidence interval.

nephritic syndrome, and liver disease suppress albumin synthesis. ${ }^{21}$ Additionally, albumin was shown to have a more important role in chronic inflammation than malnutrition. ${ }^{22,23}$ Circulating albumin has been demonstrated to play an important role in the anticancer procedure by several mechanisms, including its antioxidant function on many carcinogens, its effect on homeostasis of calcium and steroid hormone, and its negative role in cancer cell lines. ${ }^{19,20}$ Prior studies have shown that patients with lower albumin usually had worse prognosis. In 2014, Isik et $\mathrm{al}^{8}$ indicated that a level of preoperative serum albumin $<35 \mathrm{~g} / \mathrm{L}$ predicted poor prognosis for resectable gastric cancer patients. Similar results could be seen in many other cancers, including breast, ${ }^{24}$ lung, ${ }^{14}$ ovarian, ${ }^{25}$ and colorectal cancers. ${ }^{16}$ In this study, we also found that patients in the low albumin group had worse survival in comparison to those in the high group.

Similarly, high nonalbumin level was demonstrated to be associated with mortality in some cancers. Inflammatory proteins (such as C-reactive protein, interleukins, and tumor necrosis factors), which are calculated globulins, increase when inflammation occurs and can predict the occurrence of inflammation. Chronic inflammation markers take an important part in promoting tumor development, proliferation, progression, development, metastasis, and recurrence. ${ }^{22,26}$ As a chronic inflammation marker, globulin could reflect cumulative exposure to various proinflammatory cytokines such as interleukins (IL), particularly IL-6 and IL- $1 \mathrm{~b}$, and tumor necrosis factor- $\alpha .{ }^{22}$ Previous studies have shown that the expression of globulin contributes to the occurrence of various cancers, such as ovarian, ${ }^{27}$ prostate, ${ }^{28}$ and breast cancers. ${ }^{29,30}$

To our knowledge, chronic inflammation is a critical contributor to tumor growth, development progression, angiogenesis, metastasis, and recurrence. Inflammatory cells could act as powerful tumor promoters with inflammatory cytokines being released and the formation of an inflammatory microenvironment. ${ }^{31}$ We suppose that the changes in the expression levels of globulin and albumin may be a significant markers in reflecting such chronic inflammation, which influence the prognosis of gastric cancer.

Recently, AGR, combining nonalbumin and serum albumin, has been given much attention. For instance, Du et $\mathrm{al}^{32}$ proposed that low level of AGR predicted poor survival of patients with undifferentiated nasopharyngeal carcinoma. Duran et $\mathrm{al}^{33}$ also performed a retrospective study that included 240 lung adenocarcinoma patients. They concluded that low levels of AGR remained an independent factor of mortality. In colorectal cancer, Azab et al ${ }^{16}$ got a similar result. However, studies about the association between AGR and the prognosis of gastric cancer have not been performed.

In the present study, we first discovered that pretreatment AGR value can predict the prognosis of gastric cancer patients. Furthermore, lower level of AGR is found to be an effective factor in predicting worse survival.

The AGR has an advantage over a single value of just albumin or globulin in predicting prognosis. The reasons are as follows. First, AGR is a biochemistry index combined by two effective indicators, albumin and globulin; it would work better than just one of them. Second, as both of them are mainly produced by the liver, factors such as hepatic dysfunction, raw materials insufficient, and imbalance of internal environment will influence their level. Finally, the AGR test is more comprehensive and more effective to most of the primarily diagnosed patients, and it is much more accurate compared with the former (albumin or globulin alone).

On the other hand, there is still no unified method to assess the optimal cutoff points for the expression of AGR. Several methods have been applied to discover the best cutoff points. 
Azab et $\mathrm{al}^{34}$ defined the cutoff value by dividing the population into equal quartiles. In their study, patients were divided into equal tertiles according to the 33rd and 66th AGR percentile. Yao et $\mathrm{l}^{35}$ stratified globulin to albumin ratio using the receiver operating characteristics curve, and the optimal cutoff point was defined as the value at the largest Youden index.

In the present study, we defined the cutoff values using the software X-tile, in which X-plots were produced to evaluate the level of AGR based on outcome. Actually, X-tile could act as a comprehensive evaluation of all candidate methods based on the expression level of biomarkers. It could also offer a way to divide the population into training set and validation set. Similarly, using X-tile, $\mathrm{Xu}$ et $\mathrm{a}^{36}$ also determined the optimal cutoff points for PEBP1 protein levels and mRNA levels effectively and precisely.

As far as we know, the association between AGR and the prognosis of gastric cancer was first put forward in our study, which indicate that AGR should be an independent and significant factor in the diagnosis, treatment, and prediction of gastric cancer. In terms of safety and comfort, AGR measurement has the edge on other factors because it is noninvasive and it is more accurate and effective to the patients. In spite of this, further prospective studies are still needed before the clinical application of AGR.

\section{Disclosure}

The authors report no conflicts of interest in this work.

\section{References}

1. DeSantis CE, Lin CC, Mariotto AB, et al. Cancer treatment and survivorship statistics, 2014. CA Cancer J Clin. 2014;64(4):252-271.

2. Fox P, Hudson M, Brown C, et al. Markers of systemic inflammation predict survival in patients with advanced renal cell cancer. Br J Cancer. 2013;109(1):147-153.

3. McMillan DC. The systemic inflammation-based Glasgow Prognostic Score: a decade of experience in patients with cancer. Cancer Treat Rev. 2013;39(5):534-540.

4. Yamanaka T, Matsumoto S, Teramukai S, Ishiwata R, Nagai Y, Fukushima M. The baseline ratio of neutrophils to lymphocytes is associated with patient prognosis in advanced gastric cancer. Oncology. 2007;73(3-4):215-220.

5. Lee S, Oh SY, Kim SH, et al. Prognostic significance of neutrophil lymphocyte ratio and platelet lymphocyte ratio in advanced gastric cancer patients treated with FOLFOX chemotherapy. BMC Cancer. 2013;13:350.

6. Allan CA, McLachlan RI. Testosterone deficiency in men. Diagnosis and management. Aust Fam Physician. 2003;32(6):422-427.

7. Fujii T, Sutoh T, Morita H, et al. Serum albumin is superior to prealbumin for predicting short-term recurrence in patients with operable colorectal cancer. Nutr Cancer. 2012;64(8):1169-1173.

8. Isik A, Okan I, Firat D, Yilmaz B, Akcakaya A, Sahin M. A new prognostic strategy for gastric carcinoma: albumin level and metastatic lymph node ratio. Minerva Chir. 2014;69(3):147-153.

9. Heys SD, Walker LG, Deehan DJ, Eremin OE. Serum albumin: a prognostic indicator in patients with colorectal cancer. J R Coll Surg Edinb. 1998;43(3):163-168.
10. Boonpipattanapong T, Chewatanakornkul S. Preoperative carcinoembryonic antigen and albumin in predicting survival in patients with colon and rectal carcinomas. J Clin Gastroenterol. 2006;40(7): $592-595$.

11. Sun LC, Chu KS, Cheng SC, et al. Preoperative serum carcinoembryonic antigen, albumin and age are supplementary to UICC staging systems in predicting survival for colorectal cancer patients undergoing surgical treatment. BMC Cancer. 2009;9:288.

12. Lai CC, You JF, Yeh CY, et al. Low preoperative serum albumin in colon cancer: a risk factor for poor outcome. Int J Colorectal Dis. 2011; 26(4):473-481.

13. Siddiqui A, Heinzerling J, Livingston EH, Huerta S. Predictors of early mortality in veteran patients with pancreatic cancer. Am J Surg. 2007;194(3):362-366.

14. Gupta D, Lis CG. Pretreatment serum albumin as a predictor of cancer survival: a systematic review of the epidemiological literature. Nutr J. 2010;9:69.

15. Asher V, Lee J, Bali A. Preoperative serum albumin is an independent prognostic predictor of survival in ovarian cancer. Med Oncol. 2012;29(3):2005-2009.

16. Azab B, Kedia S, Shah N, et al. The value of the pretreatment albumin/ globulin ratio in predicting the long-term survival in colorectal cancer. Int J Colorectal Dis. 2013;28(12):1629-1636.

17. Washington K. 7th edition of the AJCC cancer staging manual: stomach. Ann Surg Oncol. 2010;17(12):3077-3079.

18. Camp RL, Dolled-Filhart M, Rimm DL. X-tile: a new bio-informatics tool for biomarker assessment and outcome-based cut-point optimization. Clin Cancer Res. 2004;10(21):7252-7259.

19. Sonnenschein C, Soto AM, Michaelson CL. Human serum albumin shares the properties of estrocolyone-I, the inhibitor of the proliferation of estrogen-target cells. J Steroid Biochem Mol Biol. 1996; 59(2):147-154.

20. Laursen I, Briand P, Lykkesfeldt AE. Serum albumin as a modulator on growth of the human breast cancer cell line, MCF-7. Anticancer Res. 1990;10(2a):343-351.

21. Yeun JY, Kaysen GA. Factors influencing serum albumin in dialysis patients. Am J Kidney Dis. 1998;32(6 suppl 4):S118-S125.

22. Gabay C, Kushner I. Acute-phase proteins and other systemic responses to inflammation. N Engl J Med. 1999;340(6):448-454.

23. Kaysen GA, Dubin JA, Muller HG, Mitch WE, Rosales LM, Levin NW. Relationships among inflammation nutrition and physiologic mechanisms establishing albumin levels in hemodialysis patients. Kidney Int. 2002;61(6):2240-2249.

24. Lis CG, Grutsch JF, Vashi PG, Lammersfeld CA. Is serum albumin an independent predictor of survival in patients with breast cancer? JPEN J Parenter Enteral Nutr. 2003;27(1):10-15.

25. Bizzo SM, Meira DD, Lima JM, et al. Serum albumin and vascular endothelial growth factor in epithelial ovarian cancer: looking at adnexal tumor drainage. Arch Gynecol Obstet. 2011;283(4):855-859.

26. Mantovani A, Allavena P, Sica A, Balkwill F. Cancer-related inflammation. Nature. 2008;454(7203):436-444.

27. Huang R, Ma Y, Holm R, Trope CG, Nesland JM, Suo Z. Sex hormonebinding globulin (SHBG) expression in ovarian carcinomas and its clinicopathological associations. PLoS One. 2013;8(12):e83238.

28. Kristal AR, Schenk JM, Song Y, et al. Serum steroid and sex hormonebinding globulin concentrations and the risk of incident benign prostatic hyperplasia: results from the prostate cancer prevention trial. Am J Epidemiol. 2008;168(12):1416-1424.

29. Zhou JY, Shi R, Yu HL, Zheng WL, Ma WL. Association between SHBG Asp327Asn (rs6259) polymorphism and breast cancer risk: a meta-analysis of 10,454 cases and 13,111 controls. Mol Biol Rep. 2012; 39(8):8307-8314.

30. Svartberg J, Schirmer H, Wilsgaard T, et al. Single-nucleotide polymorphism, rs 1799941 in the sex hormone-binding globulin (SHBG) gene, related to both serum testosterone and SHBG levels and the risk of myocardial infarction, type 2 diabetes, cancer and mortality in men: the Tromso Study. Andrology. 2014;2(2):212-218. 
31. Liu X, Sun X, Liu J, et al. Preoperative C-reactive protein/albumin ratio predicts prognosis of patients after curative resection for gastric cancer. Transl Oncol. 2015;8(4):339-345.

32. Du XJ, Tang LL, Mao YP, et al. The pretreatment albumin to globulin ratio has predictive value for long-term mortality in nasopharyngeal carcinoma. PLoS One. 2014;9(4):e94473.

33. Duran AO, Inanc M, Karaca $\mathrm{H}$, et al. Albumin-globulin ratio for prediction of long-term mortality in lung adenocarcinoma patients. Asian Pac J Cancer Prev. 2014;15(15):6449-6453.
34. Azab BN, Bhatt VR, Vonfrolio S, et al. Value of the pretreatment albumin to globulin ratio in predicting long-term mortality in breast cancer patients. Am J Surg. 2013;206(5):764-770.

35. Yao Y, Zhao M, Yuan D, Gu X, Liu H, Song Y. Elevated pretreatment serum globulin albumin ratio predicts poor prognosis for advanced nonsmall cell lung cancer patients. J Thorac Dis. 2014;6(9):1261-1270.

36. Xu YF, Yi Y, Qiu SJ, et al. PEBP1 downregulation is associated to poor prognosis in HCC related to hepatitis B infection. J Hepatol. 2010; 53(5):872-879.

\section{Publish your work in this journal}

OncoTargets and Therapy is an international, peer-reviewed, open access journal focusing on the pathological basis of all cancers, potential targets for therapy and treatment protocols employed to improve the management of cancer patients. The journal also focuses on the impact of management programs and new therapeutic agents and protocols on

\section{Dovepress}

patient perspectives such as quality of life, adherence and satisfaction. The manuscript management system is completely online and includes a very quick and fair peer-review system, which is all easy to use. Visit http://www.dovepress.com/testimonials.php to read real quotes from published authors. 